\title{
Manifestation of Rheumatoid Arthritis after Transsphenoidal Surgery in a Patient with Acromegaly
}

\author{
TOMOKO MIYOSHI, FUMIO OTSUKA, TOMOKO KAWABATA, KENICHI INAGAKI, TOMOYUKI MUKAI, \\ MASANORI KAWASHIMA, TOSHIO OGURA, MASAHIRO YAMAMURA, TETSURO SEI* \\ AND HIROFUMI MAKINO \\ Department of Medicine and Clinical Science, Okayama University Graduate School of Medicine, Dentistry and Pharmaceutical \\ Sciences, 2-5-1 Shikata-cho, Okayama City, 700-8558, Japan \\ *Department of Radiology, Okayama University Graduate School of Medicine, Dentistry and Pharmaceutical Sciences, 2-5-1 \\ Shikata-cho, Okayama City, 700-8558, Japan
}

\begin{abstract}
Acromegalic arthropathy is one of the most frequent manifestations occurring in acromegaly patients. In contrast, rheumatoid arthritis (RA) is a rare clinical complication in acromegaly patients. Here, we report a 70-year-old Japanese woman with acromegaly, who complained of bilateral finger stiffness and polyarthralgia two months after transsphenoidal surgery of a growth hormone (GH)-secreting pituitary adenoma. Postoperative levels of serum GH and insulin-like growth factor-1 (IGF-1) were markedly decreased without any secretory deficiency of other anterior pituitary hormones. Hand X-ray did not show typical RA changes; however, erosive changes in carpal bones were clearly detected by magnetic resonance imaging with gadolinium enhancement. Based on the levels of serological markers in the patient following surgery including C-reactive protein, rheumatoid factor and matrix metalloproteinase-3, anti-rheumatic therapy was subsequently commenced. Regardless of the levels of GH and IGF-1, acromegaly patients frequently complain about joint-related symptoms even after remission. Therefore, careful observation of bone erosive changes and immunological activity in acromegaly patients is required when joint-related symptoms persist.
\end{abstract}

Key words: Acromegaly, Arthropathy, Growth hormone, Pituitary adenoma, Rheumatoid arthritis

(Endocrine Journal 53: 621-625, 2006)

\begin{abstract}
ARTICULAR manifestations in acromegaly patients are widely recognized [1]. Arthropathy is caused by growth hormone $(\mathrm{GH})$ excess in acromegalic patients, which involves articular cartilage and nearby soft tissues [2]. At early stage, cartilage hypertrophy predominates, and then degenerative changes and osteoarthritis features appear. Acromegalic arthropathy includes axial arthropathy that involves lumbar spine [3] and peripheral arthropathy including shoulder, knee, hip, wrist and finger joints [4]. It generally de-

Received: February 24, 2006

Accepted: June 13, 2006

Correspondence to: Fumio OTSUKA, M.D., Ph.D., Department of Medicine and Clinical Science, Okayama University Graduate School of Medicine, Dentistry and Pharmaceutical Sciences, 2-5-1 Shikata-cho, Okayama City, 700-8558, Japan
\end{abstract}

velops through a non-inflammatory process, which is therefore etiologically distinct from rheumatic disorders. However, in later stages of the disease, it frequently develops into features of osteoarthritis. Here we present a rare case of acromegaly in which the patient manifested rheumatoid arthritis (RA) after surgical removal of a GH-producing pituitary adenoma. The early recognition of this complication in acromegaly patients would be clinically important to initiate timely administration of anti-rheumatic drugs.

\section{Case Presentation}

A 70-year-old Japanese female who suffered foot pain and deformity due to hallux valgus was admitted to undergo orthopedic surgery. She demonstrated typi- 

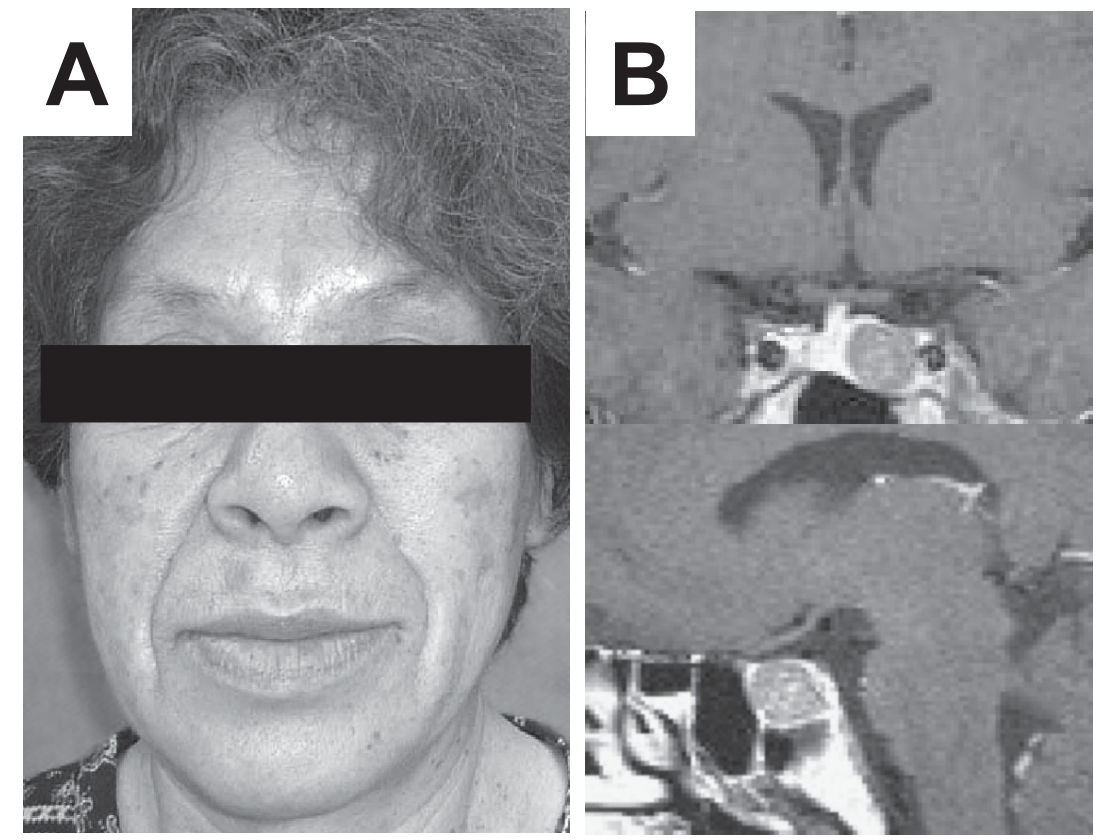

Fig. 1. Acromegalic features and pituitary MRI. A) Acromegalic face and B) pituitary MRI of coronal and sagittal views with gadolinium enhancement.

cal acromegalic facial features such as enlarged nose, bulged forehead and thickened lip (Fig. 1A). Although her previous physician noticed and documented her acromegalic features three years earlier, she refused further examinations. She had moderate hypertension and past history of colon polyps. She suffered no specific symptoms of peripheral arthralgia, including in the wrist and finger joints, although she had complained of lumbar and knee-joint pain. After surgical treatment of hallux valgus, an endocrine examination was performed. Magnetic resonance imaging (MRI) revealed a pituitary macroadenoma $(15 \mathrm{~mm}$ in diameter) in the left sellar region (Fig. 1B). Her basal GH levels were elevated in the range of $10-20 \mathrm{ng} / \mathrm{ml}$ (normal range: $0.55-3.22$ ) and she lacked normal suppression of GH by oral glucose administration. Her serum insulin-like growth factor-1 (IGF-1) level was also elevated to $704.4 \mathrm{ng} / \mathrm{ml}$ (normal: $121-436$ ), but secretion of other anterior pituitary hormones was normal based on results from pituitary stimulation tests. Prior to the pituitary surgery, the effects of octreotide $(50 \mu \mathrm{g} \mathrm{s.c.)}$ and bromocriptine ( $2.5 \mathrm{mg}$ p.o.) were examined, resulting in potent $\mathrm{GH}$ reduction to 0.58 and $0.92 \mathrm{ng} / \mathrm{ml}$, respectively. Since she had initially refused pituitary surgery, cabergoline ( 0.25 to $0.5 \mathrm{mg} /$ week p.o.) was administered for 1 year, resulting in GH and IGF-1 lev- els of $5.14 \mathrm{ng} / \mathrm{ml}$ and $549.5 \mathrm{ng} / \mathrm{ml}$, respectively. After a 16-month course of medication, she decided to undergo transsphenoidal surgery for the pituitary tumor. The resected tissues were pathologically consistent with GH-secretory adenoma. Immediately after the surgery, $10 \mathrm{mg}$ of hydrocortisone was transiently administred. The encapsulated adenoma tissues were successfully removed by a single surgery. Pituitary stimulation tests revealed that preoperative GH hyperresponse (basal to peak; 8.1 to $1143 \mathrm{ng} / \mathrm{ml}$ ) to $\mathrm{GH}$-releasing hormone (GRH) was normalized after the surgery (basal to peak; 1.3 to $13.8 \mathrm{ng} / \mathrm{ml}$ ), while other anterior pituitary hormones in responses to corticotropin-releasing hormone, thyrotropin-releasing hormone and gonadotropinreleasing hormone showed no significant deficiency compared with the preoperative responses.

However, she complained of joint-related pains including proximal interphalangeal (PIP), right elbow and right shoulder joints as well as stiffened feeling of the bilateral fingers, i.e. morning stiffness, two months after the pituitary surgery. At that time, serum levels of GH and IGF-1 were lowered to $0.44 \mathrm{ng} / \mathrm{ml}$ (blood glucose level, $91 \mathrm{mg} / \mathrm{dl}$ ) and $336.4 \mathrm{ng} / \mathrm{ml}$, respectively. Her PIP joints were bilaterally swollen with moderate heat. Immunological analysis of serum markers revealed increased levels of rheumatoid factor (RF) to 

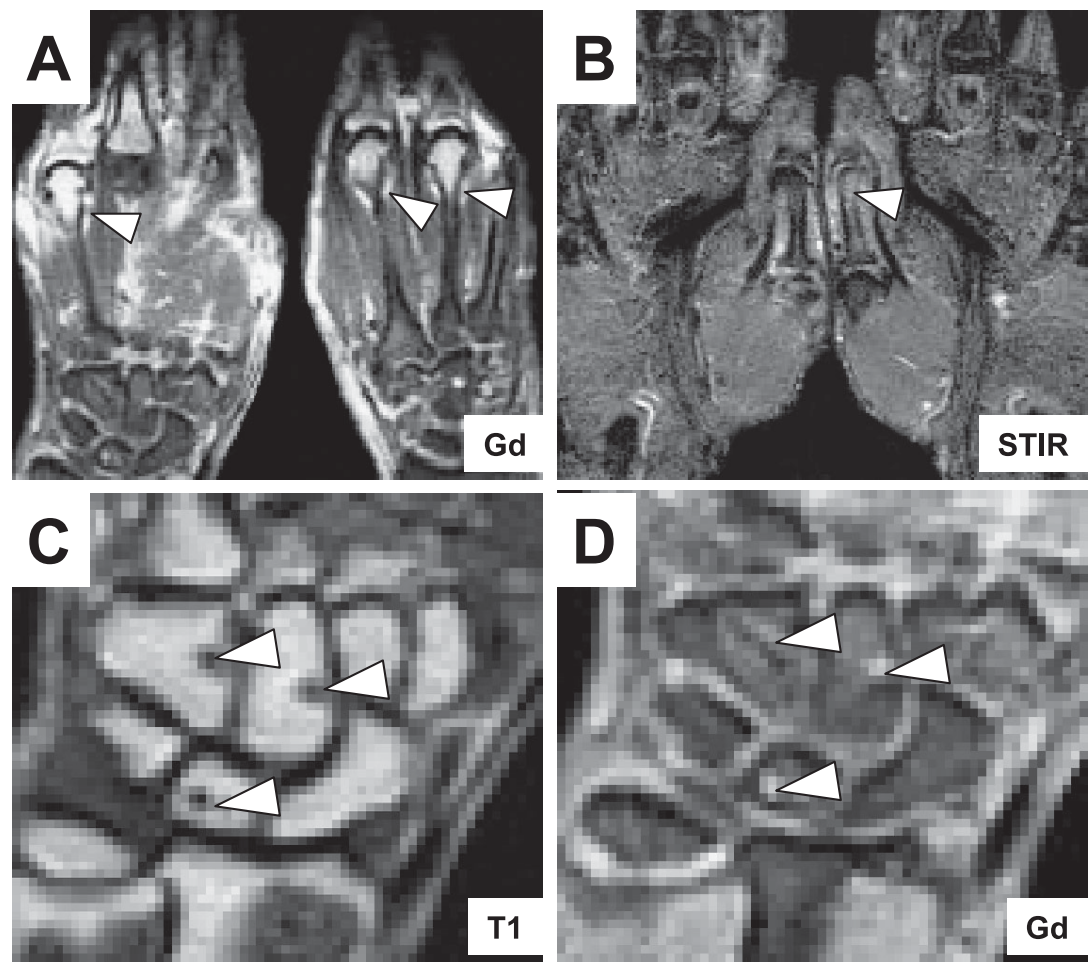

Fig. 2. Hand MRI findings. Bilateral synovitis by gadolinium (Gd) enhanced T1-image (A), bone marrow edema in the ossa metacarpi by short TI inversion recovery (STIR)-image (B), and bone erosions in the carpal bones by T1-image (C) and Gd-enhanced T1-image (D), leading to the diagnosis of early-stage RA [7, 8]. Each lesion is indicated by arrowheads.

$60.0 \mathrm{IU} / \mathrm{ml}$ (normal: <16) and positive reactions of Creactive protein (CRP) which had been previously negative (normal: $<0.3 \mathrm{mg} / \mathrm{dl}$ ). These clinical findings indicated early-stage RA based on the criteria by Japan College of Rheumatology (JCR) [5, 6]. Hand X-ray examinations showed acromegalic changes in distal phalanges although other bone changes and cartilage involvement were not detected. As shown in Fig. 2, MRI study on the hands clearly detected bilateral findings of synovitis, bone marrow edema in the ossa metacarpi, and bone erosions in the carpal bones, leading to the diagnosis of early-stage RA by rheumatologists and radiologists [7, 8]. As shown in Fig. 3, antirheumatic therapy including prednisolone (2.5 to $5 \mathrm{mg}$ ), bucillamine $(200 \mathrm{mg}$ ) and methotrexate (6 to $8 \mathrm{mg} /$ week) with non-steroidal anti-inflammatory drugs was commenced following the guidelines for early RA [9]. After 6-month medication, her polyarthralgia and morning stiffness were ameliorated with decreases in serum levels of RF and CRP, while serum levels of matrix metalloproteinase-3 (MMP-3) gradually increased from 36.4 to $158.0 \mathrm{ng} / \mathrm{ml}$ (normal: 17.3-59.7) (Fig. 3).

\section{Discussion}

Since Marie's classical description in 1886, articular manifestations of acromegaly have been widely recognized as "acromegalic arthropathy" $[2,10]$. The pathogenesis of acromegalic arthropathy is comprised of two mechanisms, initial endocrine and the subsequent mechanical changes. Early-stage acromegalic arthropathy is characterized by joint widening, hypertrophy of soft tissues and cartilage, and joint hypermobility, which are promoted by elevated GH and IGF-1 [11]. In the chronic phase, these changes develop into cartilage ulcers, subchondral cysts, arthricular narrowing, osteophyte formation, limitations of movements, and degenerative osteoarthritis, which are generally irreversible despite its non-inflammatory process [12]. Therefore, the joint-related complaints of acromegalic patients tend to be persistent even after long-term remission of acromegaly.

Complicated cases with acromegaly and RA have been rarely reported [13-16]. Among a few welldocumented reports, Ozcakar et al. [13] presented a 63 -year-old man with complaints of joint pain in the 


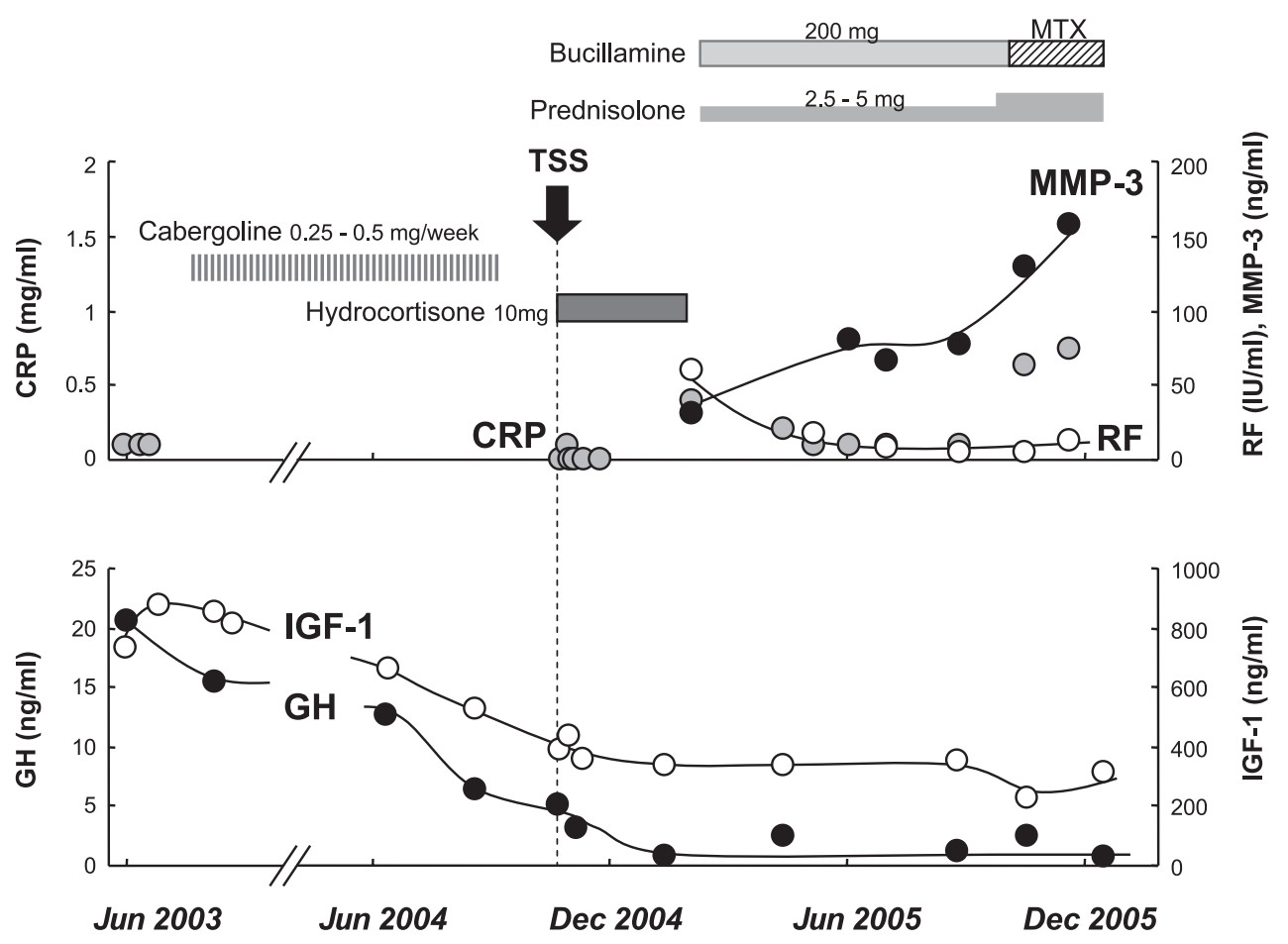

Fig. 3. Clinical course. MTX, methotrexate; TSS, transsphenoidal surgery.

knees, elbows, and shoulders and ankle swelling. Radiological and clinical findings confirmed the diagnosis of RA and the presence of concurrent acromegalic arthropathy. Read et al. [14] reported a 57-year-old woman with seropositive RA, who was diagnosed as acromegaly 12 years after the onset of RA, implying that high GH due to acromegaly might have modified the catabolic process of RA changes. Lacks and Jacobs [15] also reported a 36-year-old female acromegaly case, who had been initially diagnosed as seronegative RA and thereby treated for RA. As joint-related symptoms in this case were resolved after pituitary surgery, this arthralgia could have been solely due to acromegalic arthropathy.

According to a cross-sectional study on acromegalic arthropathy by Biermasz et al., there is no relationship between joint-related complaints and patient characteristics including age, duration of disease, and serum GH and IGF-1 concentrations [17]. In that study the only factor that was liked to the prevalence of joint pain was sex, with the female gender being associated with a higher prevalence of joint-related complaints. Since rheumatic/autoimmune disorders including RA predominantly occur in females, persistent arthropathy in female acromegaly should be carefully examined.
Interestingly, serum levels of MMP-3 remained high despite the effects of anti-rheumatic therapy on articular symptoms in our case. MMP-3 is abundantly expressed in active rheumatoid synovium, and serum level of MMP-3 is a useful marker not only for the diagnosis of RA but also for the evaluation of prognosis in bone and joint destruction [18]. Therefore, the persistent increase in MMP-3 during the treatment could be a characteristic feature seen in such RA cases complicated with acromegaly. Experimental animal studies showed that IGF-1 administration induced healing of bone defects in aged rats through activating MMP-3 expression at the defect sites [19]. In addition, MMP-3 also act to enhance IGF-1 bioavailability by degrading IGF-binding protein-3 (IGFBP-3) [20]. Based on these findings, rheumatic activity as well as concurrent effects of systemic and/or local IGF-1 excess might be involved in the underlying mechanism of sustained MMP-3 levels during RA therapy.

Regardless of the presence or absence of acromegalic arthropathy, we should consider introducing antirheumatic therapy for clinically active RA at the earliest stage. Controversial data have been reported on the possibility that acromegalic arthropathy may be modified by GH-suppressing treatment [12]. Treatment 
with octreotide was shown to improve symptoms and signs of acromegalic arthropathy $[11,21]$. Moderate improvements in pain, crepitus, and range of motion were also observed in the majority of patients treated with octreotide. Therefore, it is worth attempting to reduce serum GH and IGF-1 levels using octreotide together with concurrent RA therapy in the cases whose $\mathrm{GH}$ levels remained high after surgical treatment.
Thus, the complication of RA should be considered in acromegaly patients with joint-related symptoms. Regardless of the levels of serum GH and IGF-1, jointrelated symptoms are a frequent complaint in acromegaly patients. Hence, careful examination of bone changes and immunological activity is necessary when the symptoms persist even after successful treatment of acromegaly.

\section{References}

1. Bluestone R, Bywaters EG, Hartog M, Holt PJ, Hyde S (1971) Acromegalic arthropathy. Ann Rheum Dis 30: 243-258.

2. Barkan AL (2001) Acromegalic arthropathy. Pituitary 4: 263-264.

3. Scarpa R, De Brasi D, Pivonello R, Marzullo P, Manguso F, Sodano A, Oriente P, Lombardi G, Colao A (2004) Acromegalic axial arthropathy: a clinical case-control study. J Clin Endocrinol Metab 89: 598603.

4. Detenbeck LC, Tressler HA, O'Duffy JD, Randall RV (1973) Peripheral joint manifestations of acromegaly. Clin Orthop Relat Res: 119-127.

5. Yamamoto S, Nobunaga T, Kashiwazaki S (1993) [Study on Japan Rheumatism Association diagnostic criteria for early rheumatoid arthritis. 1. Application of the American Rheumatism Association diagnostic criteria to Japanese patients with early rheumatoid arthritis]. Ryumachi 33: 354-362 (in Japanese).

6. Yamamoto S, Kashiwazaki S, Nobunaga T (1994) [Study on Japan Rheumatism Association diagnostic criteria for early rheumatoid arthritis-2. Proposed diagnostic criteria for early rheumatoid arthritis]. Ryumachi 34: 1013-1018 (in Japanese).

7. McQueen FM, Stewart N, Crabbe J, Robinson E, Yeoman S, Tan PL, McLean L (1998) Magnetic resonance imaging of the wrist in early rheumatoid arthritis reveals a high prevalence of erosions at four months after symptom onset. Ann Rheum Dis 57: 350-356.

8. Tamai M, Kawakami A, Uetani M, Takao S, Rashid H, Tanaka F, Fujikawa K, Aramaki T, Nakamura H, Iwanaga N, Izumi Y, Arima K, Aratake K, Kamachi M, Huang M, Origuchi T, Ida H, Aoyagi K, Eguchi K (2006) Early prediction of rheumatoid arthritis by serological variables and magnetic resonance imaging of the wrists and finger joints: results from prospective clinical examination. Ann Rheum Dis 65: 134-135.

9. 2002 Guidelines for the management of rheumatoid arthritis: (2002) Update. Arthritis Rheum 46: 328-346.

10. Colao A, Pivonello R, Scarpa R, Vallone G, Ruosi C, Lombardi G (2005) The acromegalic arthropathy. $J$ Endocrinol Invest 28: 24-31.

11. Colao A, Marzullo P, Vallone G, Marino V, Annecchino M, Ferone D, De Brasi D, Scarpa R, Oriente P,
Lombardi G (1998) Reversibility of joint thickening in acromegalic patients: an ultrasonography study. J Clin Endocrinol Metab 83: 2121-2125.

12. Dons RF, Rosselet P, Pastakia B, Doppman J, Gorden $P$ (1988) Arthropathy in acromegalic patients before and after treatment: a long-term follow-up study. Clin Endocrinol (Oxf) 28: 515-524.

13. Ozcakar L, Akinci A, Bal S (2003) A challenging case of rheumatoid arthritis in an acromegalic patient. Rheumatol Int 23: 146-148.

14. Read RC, Watt I, Dieppe PA (1988) Rheumatoid arthritis and acromegaly - effect of growth factors on RA? Br J Rheumatol 27: 242-243.

15. Lacks S, Jacobs RP (1986) Acromegalic arthropathy: a reversible rheumatic disease. J Rheumatol 13: 634-636.

16. Tornero J, Castaneda S, Vidal J, Herrero-Beaumont G (1990) Differences between radiographic abnormalities of acromegalic arthropathy and those of osteoarthritis. Arthritis Rheum 33: 455-456.

17. Biermasz NR, Pereira AM, Smit JW, Romijn JA, Roelfsema F (2005) Morbidity after long-term remission for acromegaly: persisting joint-related complaints cause reduced quality of life. J Clin Endocrinol Metab 90: 2731-2739.

18. Posthumus MD, Limburg PC, Westra J, van Leeuwen MA, van Rijswijk MH (2000) Serum matrix metalloproteinase 3 in early rheumatoid arthritis is correlated with disease activity and radiological progression. $J$ Rheumatol 27: 2761-2768.

19. Blumenfeld I, Srouji S, Peled M, Livne E (2002) Metalloproteinases (MMPs-2, -3) are involved in TGFbeta and IGF-1-induced bone defect healing in 20month-old female rats. Arch Gerontol Geriatr 35: 5969.

20. Fowlkes JL, Serra DM, Bunn RC, Thrailkill KM, Enghild JJ, Nagase H (2004) Regulation of insulin-like growth factor (IGF)-I action by matrix metalloproteinase3 involves selective disruption of IGF-I/IGF-binding protein-3 complexes. Endocrinology 145: 620-626.

21. Colao A, Cannavo S, Marzullo P, Pivonello R, Squadrito S, Vallone G, Almoto B, Bichisao E, Trimarchi F, Lombardi G (2003) Twelve months of treatment with octreotide-LAR reduces joint thickness in acromegaly. Eur J Endocrinol 148: 31-38. 